\title{
Applying Group Work to Improve College Students' Oral English
}

\author{
Yongmei Jiang \\ Foreign Language School \\ Qingdao University of Science and Technology \\ Qingdao 266061, Shandong, China \\ E-mail: yongmeijiang716@126.com
}

\begin{abstract}
After a brief introduction, this paper dwells on the merits of group work, and then suggested the evaluation methods of group work. The author also mentioned the Demerits of group work and how to avoid them.

Keywords: Group work, College students, Oral English

\section{Introduction}

English as an important international language has gained increasing attention from Chinese educational institutions of different levels over more than two decades. Every Chinese college graduate has at least ten years of English learning experience. Many of them do very well in various English examinations. However, their ability to use the language in real communication does not seem to conform to the score that they have achieved. One major reason is that many Chinese classes are composed of 50 to 60 students, and most Chinese conventional EFL classrooms have been characterized by a predominance of displaying questions and an extremely high proportion of teacher-initiated interactions. The quality and amount of students' participation in EFL classes is indeed limited. Therefore, group work is definitely a good solution.
\end{abstract}

\section{The merits of Group work.}

\subsection{Group work gives students a positive affective climate.}

Language learning, to a large extent, is an emotional and psychological experience. The affective filter of the student, or some psychological factors, can obstruct language acquisition to some degree. Even understandable messages will be impeded, and language and conceptual development will not happen if a student has little motivation, lacks self-confidence, or is afraid of making errors. Obviously, in the traditional context of whole-class work, those negative psychological factors have immensely obstructed students' language acquisition and learning. Some students are afraid of making mistakes or losing face in public and are "vulnerable to what they may perceive as criticism and rejection" (Brown 1994: 174). The key then is to create a relaxed and non-threatening atmosphere in the classroom for optimal learning. Such atmosphere can be pervasive in well organized small group work. It seems easier for students to have less psychological pressure when they are thinking and speaking without being watched by a whole class or the teacher, whose higher proficiency level could also be one of the possible elements to shape the students' negative psychological factors. It is even a "magic" (Brown 1994: 174) of small group work that some silent students suddenly become active participants. It is the comfortable and safe environment of group work that has put less emphasis on the product (the right answer) and more on the process of getting an answer.

\subsection{Group work increases the students'self-confidence and self-esteem.}

College life is a very important and rememberable time in one's life. Most college students are top students in class in the previous years of school life, so, it is a key factor to help them sustain their self-confidence and self-esteem. Group work activities can build greater learner confidence and self-esteem than is likely in a competitive environment, where self-validation is dependent upon a continuing need to demonstrate success. Researchers found that students developed greater self-confidence in public speaking and in participating in classroom discussion, both situations where anxiety is likely to be the greatest and self-confidence most threatened for most language learners. An increase in self-confidence and self-esteem will lead to increased learner effort in language learning and a greater willingness to take risks or to continue attempting to make one's views understood. So group work in English classroom is very useful and important for every student to have a chance to express and demonstrate themselves, although before a very small audience.

Group work can provide a more comfortable and relaxing learning atmosphere. So the students can get more self-confidence and self-esteem from this learning atmosphere. Group provides them the opportunity to be good teachers, good helpers, good speakers and good listeners. 


\subsection{Group work promotes the students' social interaction.}

Given the psychological comfort and security in group work, students are provided with more opportunities for interaction, for giving and taking face to face, for practicing in negotiation of meanings, and for students to build social relationships. In this face to face communication, students are learning to collaborate with their peers. By applying such a learning strategy, students are promoting both their cognitive learning and interactive skills. They are exposed to new ideas and information, to different perspectives and approaches. They are in a process of discussing, questioning and organizing, which facilitates the comprehension and internalization of critical concepts and new information. As they are learning to justify and clarify their own points of view when exploring an issue or solving a problem, they are improving their linguistic competence as well as their overall communicative language competence.

In addition, Brown $(1994,159)$ asserted that "the best way to learn to interact is through interaction itself". Group work provides learners with the best stage to "show off" when they are applying what they have newly known. Students can get both intrinsic and extrinsic rewards as they are experiencing a sense of community. In group work, students may receive peer encouragement and support such as spontaneous feedback on errors. Having students work together also teaches them an important life skill - cooperation. By means of such cooperative learning, group work, affects students' attitudes and improves their interpersonal relationships, which plays an important part in their present daily and future professional life.

\subsection{Group work initiates learners' flexibility and independence, esp. in a Chinese cultural and educational context.}

Despite the merits of grouping strategies, experienced practitioners are fully aware that not all EFL learners are convinced that "four heads are better than one" (Kinsella 1993: 24). This is especially true in lots of Chinese classrooms since students are influenced by Chinese Confucian culture, which seeks compromise between people.

When it is applied to language learning, it is obvious that students are reluctant to air their views loudly for fear of losing face or offending others. In such a cultural and educational setting, the teacher dominates the whole class by generating and transferring knowledge to the learners, who sit there passively waiting to receive it. Students simply take it for granted that teachers are perfect knowledge holders and so they rarely challenge teachers, even when teachers accidentally make mistakes. In this way, a majority of students, if not all, have developed the habit of relying largely upon their teacher - the authoritative source of knowledge for everything. The time has come to have a change now from teacher-centered to learner-centered methodology. It is teachers' responsibility to encourage students not only to actively participate in various classroom activities (e.g. group work), but also to instruct students patiently about English speaking culture conventions. Thus students can be fully aware of the significance of maximizing interaction with the teacher and their peers. Therefore, it is an integral part of language teaching to make all types of learners value and benefit from this active context of learning (Kinsella \& Sherak 1993) and become more independent, flexible, as well as successful learners.

\subsection{Group work will benefit the teachers.}

Not only the students benefit from group work in English classrooms, but also the teachers. Through group work, the teachers can spare time to go around the classroom, take part in some groups or offer helps to some weak groups, therefore easily know what the students'strong points and weak points are, and which students have good understanding and active participation. In the following period, the teacher can be very clear what further explanations he needs to give, and which students could answer his questions and which could give a good report of the subject they are discussing. It is very useful for the teachers to adjust their teaching plans and helpful to know what they need to do next. As a method of teaching, teachers can use their teaching time economically and efficiently. This will help to improve the quality of language teaching.

\section{Group work evaluation}

The evaluation of the process of group work in college oral English teaching is a very important component of group work which can efficiently superintend group work and implement it's appropriately. It can also check the students' participation by a scientific system. The scientific evaluation system will be added to the grading system of college English teaching in order to make the grading system more comprehensive. The evaluation should consist of three aspects of evaluation: group members' evaluation, in-class peer evaluation and teacher's evaluation. Evaluate the following points on a scale from 1 to 5 and the total grade is 100. The general grade of group work is suggested to be divided as follows: $30 \%$ group members' evaluation $+30 \%$ in-class peer evaluation $+40 \%$ teacher's evaluation.

\subsection{Group members' evaluation}

Group members' evaluation lays emphasis on the evaluation at an angle of group peers. As group work is a process which is implemented with group mates through the whole process, the group mates observe the whole effort of the student and the evaluation can objectively reflect the participation of the student. Therefore, students in one group should provide a grade for each other in the group. The grading process can be based on the following elements and 
take into account the quality and quantity of the individual participation: punctuality, respect, honesty, ideas, creativity, and commitment preparation. The total grade of this section is 30 .

\subsection{In-class peer evaluation}

In-class peer evaluation is another important part of the evaluation system. It lays emphasis on the evaluation at an angle of in-class peers. When there's a group presentation in front of the rest of the class, the teacher can ask three or four students who are not members of the presenting collaborative group to evaluate the presentation. It is essential to set the standards for such an evaluation, so that the evaluators clearly know how and what to evaluate. The teacher can ask them to evaluate the following points on a scale from 1 to 5: fluency, body language, grammar, information, confidence, teamwork. The teacher can hand out a spreadsheet with those (or other) elements and enough space for grades and the very important element-justification.

The justification for grades in co-evaluation is very important. It's essential that students should be unbiased in their judgments and base their grading on the quality of the presentations, not on the individual's presentation. The total grade of this section is 30 .

\subsection{Teacher's evaluation}

The teacher's evaluation can evaluate whether the group work meets the requirement of the common goal. The teacher's evaluation is similar to in-class peer evaluation, which should cover the same following subjects: the fluency, body language, grammar, vocabulary, information, confidence, the regular check and teamwork. The total grade of this section is 40 .

\section{Demerits of group work}

Through the implementing of group work in the writing course, some demerits have been found in the group work of college English collaborative teaching.

\subsection{Unbalance in participations of students}

In the group work, the students with a better mastery of English and communicative competence will get more opportunities for participating. On the contrary, those who learn English poorly and have been categorized into the shy will always be the onlookers. They rarely get opportunities to think independently, but directly, learn the information from their peers who are more active participants, which leads to the result that these students learn far less in group work than in the knowledge transmission of teachers. This obviously violates the original intention of implementing group work. This problem results from the fact that the teachers and students only attach an importance to the outcome of group work, while paying no attention to the whole process of learning and to the learning process of different individuals. It also results from the improper group forming.

\subsection{Unbalance in contribution to the success of the group}

In the group work, the students with a better mastery of English often get the heavier group task and gather more information about the group task. And at the same time, based on the ability of such good students, more plans and ideas can be produced by themselves. On the contrary, the students who learn English poorly provide less information and knowledge. It can not be denied that some students have no interest in participating in group work, but the main reason of this unbalance in contribution to the success of the group is improper group forming and the poor work assignment.

\section{Conclusion}

Well-organized group work is an efficient means to improve language teaching, especially college English teaching. In discussion, students collect different information and develop a more profound understanding of knowledge through incorporating the new information into their own knowledge. By means of group work, students' linguistic competence and the ability to make use of new knowledge will be strengthened. The success of group work largely depends on implementing in the whole process. The expected effect can be reached only when it is well organized, and the teacher should be very flexible at this. For example, assign different tasks to dissimilar learner types; Let the usually taciturn learner be the reporter, the noisy one be the secretary, and the sheepish learner be the leader. When they are entrusted with roles which will require them to interact with their peers, they are learning to focus more on meaning than on grammar.

The group work implementation and tasks designing ask for the responsibility of teachers who are the designers and organizers as well as leaders and encouragers of the group work. Equipped with sufficient knowledge of linguistics, culture, psychology and pedagogy, classroom teachers in China can have enough confidence in carrying out group work.

\section{References}

Brown, H. D. (1994). Teaching by Principles: An Interactive Approach to Language Pedagogy. Englewood Cliffs, NJ: 
Printicc Hall.

Fang Xu. (2005). Sustaining CLT Through Group Work in The Chinese EFL Classroom. Chinese English Teaching: Vol.28 No.2 39-42.

Hongmei Xi. (2007). A Study on Group Work in College English Collaborative Teaching. Sino-US English Teaching: Volume 4, No.2: 1-7.

Kinsella, K. \& K. Sherak. (1993). Making group work really work: More than meets the eye. Speech at 27th Annual TESOL Convention, Atlanta, Georgia.

Kinsella, K. (1993). Designing group work that supports and enhances diverse classroom work styles. TESOL Journal $6 / 1: 22-27$. 